BMJ Open Sport \& Exercise Medicine

\title{
ACL injury incidence, severity and patterns in professional male soccer players in a Middle Eastern league
}

\author{
Raouf Nader Rekik, ${ }^{1,2}$ Montassar Tabben, ${ }^{1}$ Cristiano Eirale, ${ }^{1}$ Philippe Landreau, ${ }^{1}$ \\ Rachid Bouras, ${ }^{1}$ Mathew G Wilson, ${ }^{1,3}$ Scott Gillogly, ${ }^{1}$ Roald Bahr, ${ }^{1,4}$ \\ Karim Chamari $^{1}$
}

\begin{abstract}
To cite: Rekik RN, Tabben M, Eirale C, et al. ACL injury incidence, severity and patterns in professional male soccer players in a Middle Eastern league. BMJ Open Sport \& Exercise Medicine 2018;4:e000461. doi:10.1136/ bmjsem-2018-000461
\end{abstract}

Accepted 4 October 2018

Check for updates

(C) Author(s) (or their employer(s)) 2018. Re-use permitted under CC BY-NC. No commercial re-use. See rights and permissions. Published by BMJ.

${ }^{1}$ Aspetar Orthopedic and Sports Medicine Hospital, Doha, Qatar ${ }^{2}$ Superior Institute For Sport and Physical Education of Sfax, University of Sfax, Sfax, Tunisia ${ }^{3}$ Research Institute for Sport and Exercise Science, Liverpool John Moores University, Liverpool, UK ${ }^{4}$ Oslo Sports Trauma Research Center, Norwegian University of Sport \& Physical Education, Oslo, Norway

Correspondence to Dr Montassar Tabben Montassar.Tabben@aspetar.com

\section{ABSTRACT}

Aim To ascertain ACL injury incidence, severity (injury burden) and patterns (contact/non-contact and reinjuries) in a professional male football league in the Middle East over five consecutive seasons.

Methods Prospective epidemiological study reporting $\mathrm{ACL}$ injuries in professional male soccer players in the Qatar Stars League, with complete matches/training exposure over five seasons (2013-2014 to 2017-2018), corresponding to 2243 player seasons and 729 team months.

Results 37 complete ACL ruptures occurred in 37 players during 486951 hours of player exposure. The overall ACL injury rate was 0.076 injuries/1000 hours of exposure (season range 0.045-0.098). Injury incidence during matches and training was 0.41 and 0.04 injuries/1000 hours of exposure, respectively. Match injury incidence was greater than that of training (OR $11.8,95 \% \mathrm{Cl} 6.21$ to $23.23, \mathrm{p}<0.001)$. Average injuryrelated time-loss following ACL injury was 225 days \pm 65 (range 116-360). Overall injury burden was 16.3 days lost/1000 hours of exposure.

Conclusion The overall ACL injury rate in professional male soccer players competing in the Middle East was 0.076 injuries/1000 hours of exposure, match injury incidence was greater than training, while the average ACL time-loss was 225 days.

\section{INTRODUCTION}

An ACL injury in a professional football player is a potentially career-threatening injury. Time-loss following a complete ACL rupture is highly variable but often requires between 9 months and 12 months of rehabilitation. ${ }^{1-3}$ Furthermore, a recent study on professional footballers observed that 3 years after such an injury, only $65 \%$ of the players returned to top-level competition. ${ }^{4}$ Long-term health concerns for this injury also include the significant potential for early onset of osteoarthritis. ${ }^{5}$

While ACL injury preventative programmes have been shown to be effective, ${ }^{6-8}$ consistent with the Van Mechelen model, ${ }^{9}$ it is important
What are the new findings

- The overall ACL injury rate among professional male soccer players competing in the Middle East was similar to professional European football leagues but with a higher reinjury rate and a higher ACL training injuries rate.

How might it impact on clinical practice in the near future

- Practitioners in Middle East professional soccer now have (1) benchmark ACL injury rates to support their practice, and (2) need to improve the prevention of $\mathrm{ACL}$ injuries during training sessions and $\mathrm{ACL}$ reinjuries by understanding region-specific injury specificities.

to first define the number of injuries, their mechanism, type, location, frequency and severity in an ecologically valid population. This allows clinicians to establish appropriate prevention programmes and action plans. It is well known, for example, that ACL injuries can differ between geographical regions, ${ }^{10} 11$ climatic conditions, ${ }^{12}$ pitch grass type, ${ }^{13}$ with patterns and characteristics of ACL injuries evolving with time. ${ }^{4}$ Therefore, before ACL injury programme can be developed for the Middle East, it is essential that programme design is based on specific data representative of the region and playing conditions.

While there is a plethora of data documenting ACL injury rates in professional male sports, ${ }^{7}$ there is no such data for professional soccer players competing in the Middle East. Accordingly, the aim of this study was to ascertain the incidence, burden and patterns of ACL injuries in professional players competing in a professional football league in Qatar across five consecutive seasons. 


\section{METHODS}

\section{Study design}

This prospective epidemiological study recorded ACL injuries among professional male players from the Qatar Stars League (QSL), together with exposure data (match and training) from the 2013-2014 to the 2017-2018 season. The number of clubs involved in the injury surveillance each season was $14,16,10,15$ and 17 , respectively (first league and up to the three top professional teams of league 2). The data collection period included the preseason (July and August), as well as the two parts of the competitive season: the first half of the season (from September to December) and the second half of the season (from January to May). Only injuries occurring during the teams' activity (training and competitions) were recorded, that is, any injury occurring outside the teams' activity were excluded. The study population included 407 (2013/2014), 527 (2014/2015), $324(2015 / 2016), 496(2016 / 2017)$ and 489 (2017/2018) players, respectively, corresponding to 2243 player seasons and 729 team months.

Injuries and match/training exposure (individual players' minutes of training and match play) were obtained from the Aspetar Injury and Illness Surveillance Program, recorded by medical staff assigned to each QSL club on behalf of Aspetar's National Sports Medicine Programme, as previously described. ${ }^{14} 15$ All medical staff used a standardised injury reporting system that has been established based on the consensus statement on injury definitions and data collection procedures in previous soccer injuries studies. ${ }^{1116}$

\section{Injury definition}

ACL injuries were confirmed as complete ruptures on MRI (by the hospital radiologist) and in all but one case through arthroscopy. Partial ACL ruptures were not included. A standardised injury card was completed for each injury, specifying the diagnosis, the injured side (right or left leg) and if the injury was caused by contact (collision with another player/object). Contact injuries included both direct and indirect contact, ${ }^{17}$ that is, contact with the knee and contact with another body part, respectively. A reinjury was defined as a complete graft rupture occurring in a reconstructed knee during the study period. Time-loss was calculated from the date of injury to the date of return to full participation (player being medically discharged and ready for full unrestricted training and match play). For injury burden calculations, the closing date was chosen as the last day of season 5 for players who had not returned to full participation yet. All data were reviewed for completeness, with medical and diagnostic accuracy rechecked with the clubs' team physician if required. A data double-check with an independent ACL research group within Aspetar was performed to establish data completeness.

\section{Statistical analyses}

Actual exposure during training and matches was calculated separately for each player. The injury incidence was expressed as rate per 1000 hours of exposure and calculated as: (number of injuries/hours of exposure to risk, ie, game or training $) \times 1000$. Injury burden was calculated as: (number of days lost/hours of exposure to risk, ie, game or training) $\times 1000$. In addition, Poisson $95 \%$ CIs were calculated for the incidence rates, and difference between incidence rates was calculated using techniques described by Frome and Checkoway. ${ }^{18}$ All above computations were performed using StatsDirect statistical software V.2.7.8. A linear regression analysis under SPSS Statistics software (V.25.0) was used to analyse the time trend of the incidence rates across the five seasons. Cut-off for statistical significance was set at $\mathrm{p}<0.05$.

\section{RESULTS}

\section{Overall injury incidence and burden}

A total of 37 ACL injuries were recorded in 37 players over the five seasons. On average, ACL injured players were 25.0 \pm 3.8 years old (range: $18.6-32.0$ ) at the time of injury. Measured at the start of the season of the ACL injury, height, body mass and body mass index of the injured players was $176.7 \pm 7 \mathrm{~cm}$ (range: $163-190), 74.04 \pm 8.7 \mathrm{~kg}$ (range: $60-92$ ), and $23.6 \pm 1.6 \mathrm{~kg} / \mathrm{m}^{2}$ (range: $20.4-27.1$ ), respectively. There were $30 \mathrm{Arab} / \mathrm{Maghrebans}, 3$ black Africans, 3 Asians (2 Persians and 1 Indonesian) and 1 Caucasian. ${ }^{19}$

There were a total of 486951 hour of player exposure over five seasons ( 72 club seasons), resulting in an overall ACL injury rate of $0.076 / 1000$ hours of exposure (95\% CI 0.053 to 0.104 ; season range $0.045-0.098)$. ACL injuries occurred to five goalkeepers $(13.5 \%), 12$ defenders (32.4\%), 15 midfielders (40.6\%) and 5 strikers (13.5\%). There was no significant difference in ACL injury incidence rate across the five seasons $(\mathrm{Y}=0.011 \mathrm{x}+0.087$, $\mathrm{p}=0.89$, figure 1 ). On average, there were 7.4 ACL injuries per season, representing 0.51 ACL injuries by team per season. Of the 37 ACL injuries, 36 were surgically reconstructed with one case opting for conservative treatment. There were three $(8.1 \%)$ ipsilateral reinjuries, and no contralateral ACL injuries. In all of the reinjury cases, the index injury occurred prior to the 2013/2014 season.

\section{Time-loss}

The overall injury burden for ACL injuries was 16.3 days lost per 1000 hours of exposure across the five seasons (95\% CI 16.0 to 16.7$)$. The duration of time-loss was available for 30 players (225.4 \pm 65.0 days, range 116-360, with a median of 204.5 days), as seven players were still undergoing rehabilitation as of end of June 2018 (end of season 5).

\section{Injury time point within the season}

Of the 37 injuries, 9 occurred in the preseason (incidence: 0.093 injuries $/ 1000$ hours; $95 \%$ CI 0.042 to 0.178 ), 14 in the first half $(0.069 ; 95 \%$ CI 0.037 to 0.116$)$ and 14 in the 


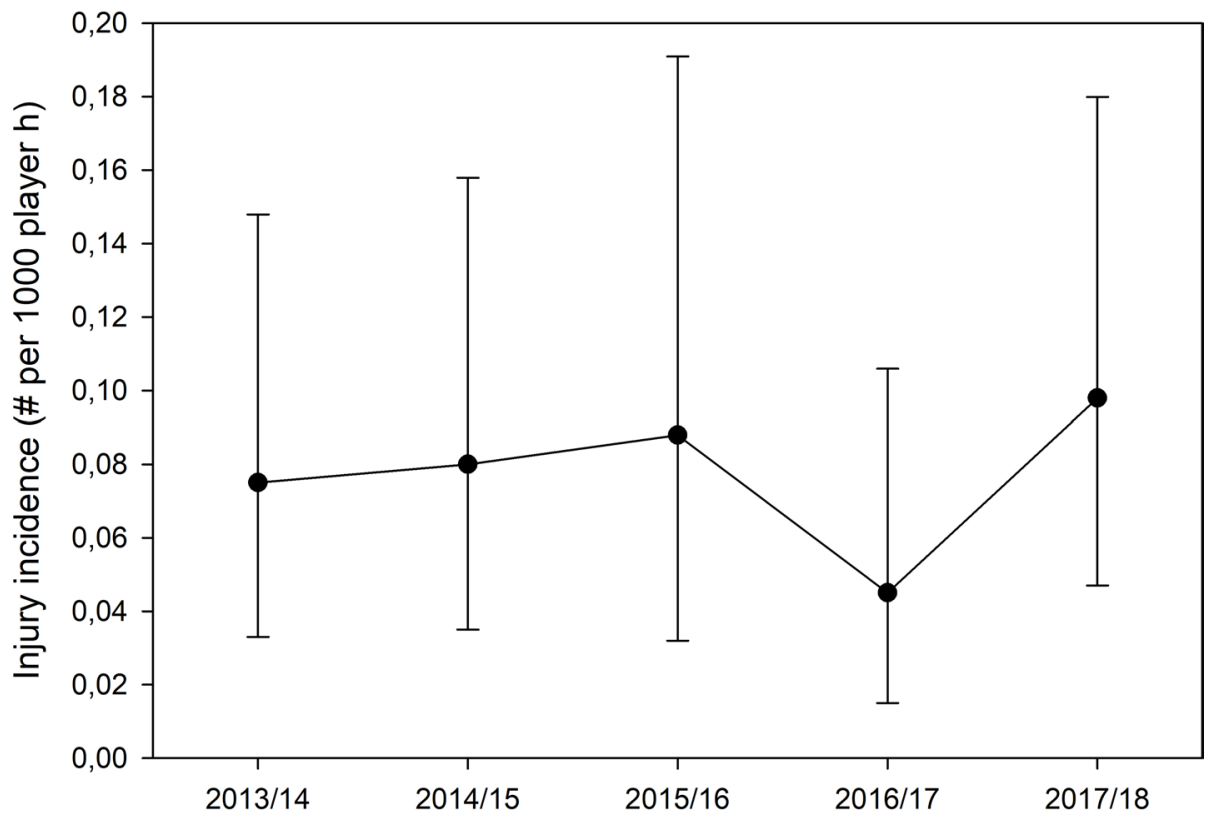

Figure 1 Incidence of ACL injuries during the five seasons with $95 \% \mathrm{Cls}$.

second half $(0.074 ; 95 \%$ CI 0.040 to 0.124$)$ of the season, respectively. There were no significant differences in injury incidence between these three time points.

\section{Injury circumstances}

Of the 37 injuries, 22 occurred during matches and 15 during training, with an injury incidence of $0.41(95 \%$ CI 0.26 to 0.63 ) and 0.04 (95\% CI 0.02 to 0.06$)$ per 1000 hours of exposure, respectively. The injury incidence in matches was greater than that of training (OR 11.8, 95\% CI 6.21 to $23.23, \mathrm{p}<0.001)$. Of the 37 ACL injuries, 18 (48.6\%) occurred from contact (both direct and indirect) versus $19(51.4 \%)$ from non-contact mechanisms.

\section{DISCUSSION}

The main findings of this prospective cohort study were that from a total of 486951 hours of player exposure over five seasons ( 72 club seasons), the overall ACL injury rate among professional male soccer players competing in the Middle East was of 0.076/1000 hours of exposure, there were no significant differences in ACL injury incidence rate across the five seasons, ACL injury rates occurring during matches were significantly greater than during training and, finally, average ACL time-loss was 225.4 days.

\section{ACL injury incidence}

The incidence for overall ACL injuries observed in the present study is similar to data reported by the UEFA Elite Clubs Study (0.076 vs 0.066 injuries/1000 hours, respectively). ${ }^{4}$ Unlike the present study, however, UEFA observed a non-significant $6 \%$ average annual increase in ACL injury rates. ${ }^{4}$ Practically, the data of the present study demonstrates that each team involved in the QSL may expect to have 0.51 ACL injury per season (or approximately one ACL injury per two seasons) which, importantly, does not appear to be higher than injuries rates reported elsewhere in the literature. ${ }^{410}$

ACL injuries occurring during matches in the present study were similar to the UEFA study ( 0.41 vs 0.34 injuries/1000 hours, respectively). ${ }^{4}$ However, the present study demonstrates that, unlike the UEFA study, ACL injuries occurring during training were much higher (0.017 vs 0.035 injuries/1000 hours, respectively), with training injury rate being 20 times lower than match rate in the UEFA study and only 11.8 times lower than match rate in Qatar. This difference could potentially be explained by increased training exposure compared with matches. In Qatar, during the five seasons studied, 12 or 14 teams played 22 or 26 local league matches per season. In three major football leagues in Europe (England, Spain and Italy), there are 20 teams playing a minimum of 38 domestic matches per season, more if qualifying for UEFA Champions League. Overall, the number of matches played in Qatar over one season is considerably lower compared with most European leagues, and thus, the ratio of training-to-match exposure is higher in Qatar and may account for our greater ACL injury rate occurring in training.

The absence of seasonal fluctuation of the of ACL injury rate in this study is comparable with other studies within the literature, ${ }^{40}$ and thus, there does not appear to be any period of the QSL season at greater risk for ACL injury. However, the ACL reinjury rate observed in the present study was $8.1 \%$, which is approximately two times greater than in the UEFA study $(3.82 \%) .{ }^{4}$ Exact reasons for our higher reinjury rates are unclear at present. However, a study done in our hospital included athletes who had ACL reconstruction between 1 January 2008 and 21 September 2015 and found two risk factors for graft rupture before returning to play: not meeting 
six discharge criteria (functional tests and muscle strength) and decreased hamstring to quadriceps ratio of the involved leg at $60^{\circ} / \mathrm{s} .{ }^{21}$ In this context, practitioners should evaluate return to competition criterion and compliance with rehabilitation before considering their athletes fit to return to play. Furthermore, there is controversy about the ACL injury prevention efficiency in literature, ${ }^{22} 23$ although recent papers are bringing evidence about the role of the FIFA 11+ warm up prevention programme to decrease ACL injurie. ${ }^{24}$ Therefore, practitioners in Middle East professional soccer need to consider improving the prevention of (1) ACL injuries during training sessions and (2) ACL reinjuries, even though literature does not bring evidence of easy to implement and efficient protocols yet.

Another potential injury risk factor may come from the quality of the pitches on which players train (pitch hardness, rotational traction for instance and/or evolution across the season). ${ }^{25}$ Anecdotal subjective reports suggest that the QSL training pitches are of a lower standard than match pitches. The relationship between pitch characteristics, boot type and foot/field interaction and ACL injury mechanisms merits more scrutiny and research.

\section{ACL injury time-loss}

The median absence of 204.5 days is in line with the 199.5 days reported in the UEFA Elite Club Study, ${ }^{4}$ and the average time-loss by player after ACL injury was of 225.4 days. With such comparable injury and time-loss rates between the QSL and UEFA, it confirms there is no major variation in ACL injuries in the Middle East compared with European football. However, strategies to decrease ACL incidence during training and improving reinjury rates are paramount in the Middle East.

From the perspective of post-ACL injury management, shortening return-to-play times may seem attractive from a performance and player availability standpoint; it may present significant challenges to the players future health. ${ }^{15}$ The debate on time to return to play is controversial, with rerupture and early onset of osteoarthritis at the forefront of this debate. ${ }^{7}$

\section{ACL injury mechanism}

The present study demonstrated that $51.4 \%$ of ACL injuries occurred via a non-contact mechanism, consistent $(58 \%)$ with other professional European professional leagues. ${ }^{26}$ In a video analysis study of non-contact ACL injuries, three distinct mechanisms were evident in male professional soccer players: (1) pressing followed by kicking and heading; (2) knee valgus regardless of the playing situation; (3) and rarely: dynamic valgus collapse. ${ }^{27}$ Such precise mechanism analysis could improve ACL injury prevention exercises targeting specific injury mechanisms, and therefore, further largescale video analysis studies of ACL injuries in players competing in the Middle East are warranted in order to better understand region specific ACL injury mechanisms.

\section{Methodological considerations}

The present study is the first in Qatar and Middle East to assess the epidemiology of ACL injuries among professional male soccer players. It respected the consensus statement of soccer injury surveillance. ${ }^{16}$ Its strength is in the reliability of data monitoring and the sample size encompassing the vast majority of Qatari professional teams. The teams involved in the study included up to three teams from second division. Having two different leagues with different playing styles and standard of players could constitute a limitation for this study, but it should be noted that these three teams were also professional teams. The challenge also of having a non-constant number of teams followed by season was counteracted by the fact that we had precise and complete exposure data. While there is still a risk of data under-reporting with such epidemiological studies, our facility is the sole provider in Qatar of treating ACL injuries in athletes, which also employ all QSL club medical staff and ACL researchers. Furthermore, we cross-checked our data with another independent group from the hospital treating ACL injuries for data completeness. Data quality could be improved in the context of ACL injuries by better reporting on mechanism of injury. Indeed, in these injuries, some will result from direct contact, that is, a tackle to the knee, for instance, but others can result from indirect contact, that is, a shock to another body part resulting in an injury to the knee. ${ }^{17}$ In this context, this study groups both direct and indirect contact injury mechanisms with no distinction.

\section{CONCLUSION}

In conclusion, the overall ACL injury rate among professional male soccer players competing in the Middle East was $0.076 / 1000$ hours of exposure and is comparable with professional European football leagues. While there were no significant differences in ACL injury incidence rate across the five seasons, ACL injury rates occurring during matches was significantly greater than in training. This study serves as basis for establishing ACL injury prevention programmes that is specific to players playing in the Middle East.

Acknowledgements The authors would like to thank all the doctors, physiotherapists and nurses from the National Sports Medicine Program (NSMP) that are collecting data for the Aspetar Injury and IIIness Surveillance Program.

Contributors All authors contributed to the study design and data recoding preparation. MT, KC, CE, RNR and RoB were responsible for the data collection and data analysis. RNR, MT and KC interpreted the data and wrote the first draft of the paper. All authors contributed to the final paper. RNR and KC are responsible for the overall content as guarantors.

Funding The authors have not declared a specific grant for this research from any funding agency in the public, commercial or not-for-profit sectors.

Competing interests None declared.

Patient consent Not required.

Ethics approval The study was approved by the Anti-Doping Laboratory Qatar Ethics Institutional review board (IRB E2017000252).

Provenance and peer review Not commissioned; internally peer reviewed. 
Open access This is an open access article distributed in accordance with the Creative Commons Attribution Non Commercial (CC BY-NC 4.0) license, which permits others to distribute, remix, adapt, build upon this work non-commercially, and license their derivative works on different terms, provided the original work is properly cited, appropriate credit is given, any changes made indicated, and the use is non-commercial. See: http://creativecommons.org/licenses/by-nc/4.0/

\section{REFERENCES}

1. Zaffagnini S, Grassi A, Marcheggiani Muccioli GM, et al. Return to sport after anterior cruciate ligament reconstruction in professional soccer players. Knee 2014;21:731-5.

2. Roi GS, Creta D, Nanni G, et al. Return to official Italian first division soccer games within 90 days after anterior cruciate ligament reconstruction: a case report. J Orthop Sports Phys Ther 2005;35:52-66.

3. Weiler R, Monte-Colombo M, Mitchell A, et al. Non-operative management of a complete anterior cruciate ligament injury in an english premier league football player with return to play in less than 8 weeks: applying common sense in the absence of evidence. BMJ Case Rep 2015;2015:bcr2014208012

4. Waldén $M$, Hägglund $M$, Magnusson $H$, et al. ACL injuries in men's professional football: a 15-year prospective study on time trends and return-to-play rates reveals only $65 \%$ of players still play at the top level 3 years after ACL rupture. Br J Sports Med 2016;50:744-50.

5. von Porat A, Roos EM, Roos H. High prevalence of osteoarthritis 14 years after an anterior cruciate ligament tear in male soccer players: a study of radiographic and patient relevant outcomes. Ann Rheum Dis 2004;63:269-73.

6. Gilchrist J, Mandelbaum BR, Melancon $\mathrm{H}$, et al. A randomized controlled trial to prevent noncontact anterior cruciate ligament injury in female collegiate soccer players. Am J Sports Med 2008;36:1476-83.

7. Bisciotti GN, Chamari K, Cena E, et al. ACL injury in football: a literature overview of the prevention programs. Muscles Ligaments Tendons J 2016;6:473-9.

8. Ramírez-Campillo R, Meylan C, Alvarez C, et al. Effects of in-season low-volume high-intensity plyometric training on explosive actions and endurance of young soccer players. J Strength Cond Res 2014;28:1335-42.

9. van Mechelen W, Hlobil H, Kemper HC. Incidence, severity, aetiology and prevention of sports injuries. A review of concepts. Sports Med 1992;14:82-99.

10. Waldén M, Hägglund M, Orchard J, et al. Regional differences in injury incidence in European professional football. Scand J Med Sci Sports 2013;23:424-30.

11. Eirale C, Gillogly S, Singh G, et al. Injury and illness epidemiology in soccer - effects of global geographical differences - a call for standardized and consistent research studies. Biol Sport 2017;34:249-54.

12. Orchard JW, Waldén $M$, Hägglund $M$, et al. Comparison of injury incidences between football teams playing in different climatic regions. Open Access J Sports Med 2013;4:251-60.

13. Orchard JW, Chivers I, Aldous D, et al. Rye grass is associated with fewer non-contact anterior cruciate ligament injuries than bermuda grass. Br J Sports Med 2005;39:704-9.

14. Eirale C, Farooq A, Smiley FA, et al. Epidemiology of football injuries in Asia: a prospective study in Qatar. J Sci Med Sport 2013;16:113-7.

15. Eirale $\mathrm{C}$, Tol JL, Farooq $\mathrm{A}$, et al. Low injury rate strongly correlates with team success in Qatari professional football. Br J Sports Med 2013;47:807-8

16. Fuller CW, Ekstrand J, Junge $\mathrm{A}$, et al. Consensus statement on injury definitions and data collection procedures in studies of football (soccer) injuries. Clin J Sport Med 2006;16:97-106.

17. Olsen OE, Myklebust G, Engebretsen L, et al. Injury mechanisms for anterior cruciate ligament injuries in team handball: a systematic video analysis. Am J Sports Med 2004;32:1002-12.

18. Frome EL, Checkoway H. Epidemiologic programs for computers and calculators. Use of poisson regression models in estimating incidence rates and ratios. Am J Epidemiol 1985;121:309-23.

19. Lin SS, Kelsey JL. Use of race and ethnicity in epidemiologic research: concepts, methodological issues, and suggestions for research. Epidemiol Rev 2000;22:187-202.

20. Schiffner E, Latz D, Grassmann JP, et al. Anterior cruciate ligament ruptures in German elite soccer players: Epidemiology, mechanisms, and return to play. Knee 2018;25:219-25

21. Kyritsis P, Bahr R, Landreau P, et al. Likelihood of ACL graft rupture: not meeting six clinical discharge criteria before return to sport is associated with a four times greater risk of rupture. Br J Sports Med 2016;50:946-51.

22. Grimm NL, Jacobs JC, Kim J, et al. Anterior cruciate ligament and knee injury prevention programs for soccer players: a systematic review and meta-analysis. Am J Sports Med 2015;43:2049-56.

23. Dai B, Mao D, Garrett WE, et al. Anterior cruciate ligament injuries in soccer: Loading mechanisms, risk factors, and prevention programs. J Sport Health Sci 2014;3:299-306.

24. Silvers-Granelli $\mathrm{H}$, Mandelbaum B, Adeniji O, et al. Efficacy of the FIFA 11+ injury prevention program in the collegiate male soccer player. Am J Sports Med 2015;43:2628-37.

25. Caple M, James I, Bartlett M. Mechanical behaviour of natural turf sports pitches across a season. Sports Engineering 2012;15:129-41.

26. Waldén $\mathrm{M}$, Hägglund $\mathrm{M}$, Magnusson $\mathrm{H}$, et al. Anterior cruciate ligament injury in elite football: a prospective three-cohort study. Knee Surg Sports Traumatol Arthrosc 2011;19:11-19.

27. Waldén M, Krosshaug T, Bjørneboe J, et al. Three distinct mechanisms predominate in non-contact anterior cruciate ligament injuries in male professional football players: a systematic video analysis of 39 cases. Br J Sports Med 2015;49:1452-60. 